\title{
Design and Modeling of Selective Reinforcements for Integral Aircraft Structures
}

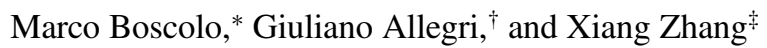 \\ Cranfield University, Bedfordshire, England MK43 OAL, United Kingdom
}

DOI: $\underline{10.2514 / 1.35712}$

\begin{abstract}
A numerical simulation is presented in this paper on the performance of crack retarders bonded to integral metallic structures. The work is described in two main parts. First, a novel modeling approach employing the finite element method has been developed for simulating the various failure mechanisms of a bonded structure and for predicting fatigue crack growth life. Crack growth in the substrate and the substrate/strap interface disbond failure are modeled in the framework of linear elastic fracture mechanics. A computer code interfacing with the commercial package MSC NASTRAN has been developed and validated by experimental tests. Second, the effectiveness of different strap configurations on crack growth retardation has been modeled; these include different strap materials, strap dimensions, and their locations on the substrate. The research has included two substrate materials and four strap materials, and at this stage the specimens were cured at room temperature. Strap stiffness and adhesive toughness are found to be the most influential parameters in designing crack retarders. A design tool has been developed based on the numerical simulation to achieve optimal crack retarder design in terms of prescribed fatigue life target and minimum structural weight added by the bonded reinforcement.
\end{abstract}

\section{Introduction}

I NTEGRAL structures for aircraft fuselage and wing assemblies allow the achievement of significant weight savings as well as cost reductions. Manufacturing processes, such as welding, casting, forging, large-scale extrusion, and high-speed machining, will permit modular prefabrication of large sections of an aircraft before final assembly $[\underline{1}, 2]$. This is especially true for skin-stringer panels, which constitute the main component of aircraft wing and fuselage shells. Integral "unitized" panels benefit from the absence of crack initiation sources compared with the traditional built-up structures, for example, riveted panels. However, integral panels lack the capability of retarding or arresting crack propagation due to the lack of redundant members. For this reason, regulators penalize unitized structures by imposing an additional design safety factor.

One promising solution is to use bonded straps as crack growth retarders for integral structures [3-ㅛ] . The concept is illustrated in Fig. 1. These selective reinforcement straps could be made of fiber polymer composites, fiber-metal laminates (FML), or metallic alloys. Unlike the repair patches [9-15], which are used when fatigue cracks are detected, these crack retarders will be part of the original aircraft structure and subjected to operational loads and environments throughout the entire service life. The damage tolerance capability is added to the integral panels ab initio. In this way, safer, lighter, and cheaper structures can be built and the role of metallic structures in future aircraft reevaluated.

Some studies have been carried out to evaluate the bonded selective reinforcement. In 1990, Schijve [3] reported his work on bonded crack stoppers bands using either a fiber-metal laminate named ARALL, an aluminum alloy, or a titanium alloy. These straps were either riveted or bonded to the aluminum substrate. Fatigue crack growth tests showed that the best strap materials were the

Presented as Paper 2116 at the 48th AIAA/ASME/ASCE/AHS/ASC Structures, Structural Dynamics, and Materials Conference, Honolulu, Hawaii, 23-26 April 2007; received 16 November 2007; revision received 20 March 2008; accepted for publication 6 April 2008. Copyright $\odot 2008$ by Cranfield University. Published by the American Institute of Aeronautics and Astronautics, Inc., with permission. Copies of this paper may be made for personal or internal use, on condition that the copier pay the $\$ 10.00$ per-copy fee to the Copyright Clearance Center, Inc., 222 Rosewood Drive, Danvers, MA 01923; include the code 0001-1452/08 \$10.00 in correspondence with the CCC.

${ }^{*} \mathrm{Ph}$.D. Student, Aerospace Engineering Department. Member AIAA.

Lecturer, Aerospace Engineering Department. Member AIAA.

${ }^{\ddagger}$ Senior Lecturer, Aerospace Engineering Department. Member AIAA.
ARALL and titanium alloy. Recently, only bonded straps were studied, because riveting would introduce stress concentration spots. Heinimann et al. [4] tested different strap configurations and materials (GLARE- $\overline{1}$, aluminum 7075-T762, and carbon-epoxybased fiber-metal laminates) on aluminum substrates and obtained excellent results. Wide panels with seven bonded GLARE-1 straps were tested. The straps were stretched to reverse the bonding residual stress in the aluminum substrate from tension to compression. The results were good; the thinnest test panels had the largest reinforcement volume fraction $(28 \%)$ and achieved an average fatigue life improvement of more than $300 \%$. Other tests were carried out on aluminum panels reinforced by GLARE and unidirectional (UD) carbon-epoxy fiber-metal laminates. The tensile residual stresses induced by the cure cycle were reduced by pinning the grip ends of the substrate and straps during the cure process. In this way, the fatigue crack growth (FCG) life can be significantly increased. Zhang and Li [5] studied by numerical simulation integral stringer panels reinforced by either UD carbon-epoxy laminates or Ti-6Al$4 \mathrm{~V}$ straps. The finite element method (FEM) was used to model crack growth and disbond failure. Based on the numerical modeling, the FCG life was significantly improved by both types of bonded straps. Tests and finite element (FE) modeling were conducted by Colavita et al. [6] and Bowler [7] using carbon-epoxy straps on an aluminum plate. They found the adverse effect of thermal residual stresses arising from curing the adhesive at an elevated temperature, which actually reduced the life of the strapped integral structure compared with the unreinforced one.

The objective of the work reported in this paper is to develop a modeling approach based on the finite element method and using a fracture mechanics based failure criterion. A study of the strap materials and geometries has been carried out for structural applications and a design tool has been developed.

\section{State of the Art in Modeling Techniques for Bonded Structures}

Although bonded patch repairs and bonded selective reinforcement are two different concepts, the phenomena in retarding fatigue crack growth rate are similar. If a crack grows in the substrate, the bonded strap retards the crack propagation by exerting a bridging force at the crack surfaces. However, damage may also develop in the strap; for example, due to the stiffness mismatch and high stress concentration, the strap/skin interface is affected by a progressive delamination or disbond, which advances together with the substrate 
crack and limits the strap bridging action. Both subjects have been studied and the modeling techniques are reviewed later.

The work of many researchers [9-15] has resulted in the development of a repair scheme employing a bonded composite patch. The bonding process is very effective because it provides a load transfer into the patch without introducing any stress concentration into the structure. The main drawback is that the curing process of the adhesive requires an elevated temperature and pressure that generate thermal residual stresses in the substrate. A list of applications of patch repair techniques can be found in Baker [10]. Important aspects are the choice of the patch material, surface treatment, and adhesive selection.

On the analysis front, the aim has been to determine the stress intensity factor (SIF) values and stresses or strains in the patch and adhesive system. Analytical and numerical methods have been developed to study patch repairs [9-15], but none of these is able to study the delamination/disbond growth in the adhesive interface. One method has been developed by Naboulsi and Mall [12] that employs 2-D Mindlin plate elements to model the substrate, adhesive, and patch. The contribution of the rotation movement to the strain energy release rate (SERR) was considered using the modified virtual crack closure technique [16] (MVCCT or VCCT). This model, often referred to as the "three-layer technique," is the most employed, but disbond is not entirely taken into account. In fact, disbond shape and size are prescribed as a function of the substrate crack length by observing the test results. Moreover, the progressive growth of the disbond with the substrate crack length and its effect on the final FCG life of the structure were not studied. Only the SERR was computed along the disbond front (which was assumed to be elliptical). Sun et al. [13] as well as Colombi et al. [8] studied disbond in the same way, that is, by prescribing an elliptical disbond shape and computing the SERR on its front. In Sec. III, a new modeling technique will be introduced, and, by this technique, a progressive disbond can be computed.

Zhang and $\mathrm{Li}$ [5] modeled integral stiffened panels with bonded unidirectional carbon-epoxy and Ti-6AL-4V straps. In this case, 2-D plate elements were employed for the straps and aluminum substrate, and three spring elements were employed for the adhesive. The failure of the adhesive and the disbond growth were studied. The adhesive failure was modeled by a strength-based criterion, and the failure of the spring elements was imposed when either the von Mises stress or interlaminar shear stress exceeded the allowable. This method is able to calculate the disbond, but the stress values in the FE models are mesh dependent. The SIF solution was integrated by the AFGROW code [17] to obtain fatigue crack growth life.

\section{A. Two-Layer-Plus-Spring Model}

\section{Modeling Approach}

The main challenge in predicting the potential of bonded composite straps as crack retarders by FE models is the understanding and modeling of the different failure mechanisms that affect the strap/substrate assembly. These are the lead crack in the substrate, the disbond growth in the adhesive interface, and their interactions. A computer program, interfaced to the $\mathrm{MSC} /$ NASTRAN commercial finite element package, has been developed to model the previously mentioned failure modes, calculate the SIF for progressive crack lengths, and predict the fatigue crack growth life of strapped plates. This program is based on a particular modeling technique developed by the authors, which is referred as the "two-layer-plus-spring" model. This paper reports the first-stage work, in which only the room temperature cured adhesives were modeled to exclude the thermal residual stress effect.

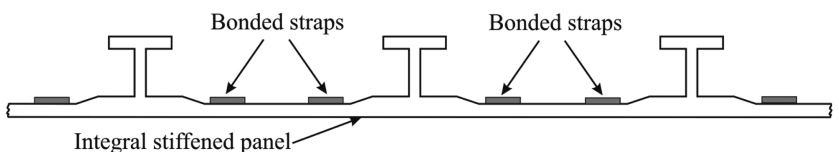

Fig. 1 Integral stiffened panel with selective reinforcements.
The FE models employ 2-D plate elements for the substrate, 2-D laminate/plate elements for the strap, and interface elements for the adhesive. Each of the interface elements contains two rigid elements to model the thickness of the adhesive and three coincident spring elements for each pair of nodes at the strap/substrate interface to model the peel and shear properties of the adhesive (Fig. 2). The adhesive model was developed by Tahmasebi [18] for analysis of bonded joints, and it was used in this work to simulate the behavior of the adhesive in the bonding interface due to the convenience of being able to delete the spring elements as the disbond failure progresses. The stiffness of the spring elements $\left(K_{a z}, K_{a x}\right.$, and $\left.K_{a y}\right)$ along the three directions can be computed by using the following equations:

$$
K_{a z}=\frac{A_{a} E_{a}}{t_{a}}, \quad K_{a x}=K_{a y}=\frac{A_{a} G_{a}}{t_{a}}
$$

where $A_{a}$ is the equivalent area of the adhesive element (one-quarter of the area of each plate element it is connected to [18]), $E_{a}$ is the adhesive elastic modulus, $G_{a}$ is the adhesive shear modulus, and $t_{a}$ is the adhesive thickness.

Linear elastic fracture mechanics are used to calculate the principal parameters that govern the fracture failure. Through the FE analysis and the MVCCT technique [16], the strain energy release rate, SERR or $G$, on the disbond front of the adhesive is computed for a given lead crack length $(a)$ and for every fracture mode (I, II). The strain energy release rate is computed for each group of springs at the disbond periphery. Using a mixed mode failure criterion [Eq. (2)], the failed adhesive elements are found and deleted to simulate adhesive disbond progression:

$$
\frac{G_{\mathrm{I}}}{G_{\mathrm{IC}}}+\frac{G_{\mathrm{II}}}{G_{\mathrm{IIC} C}} \geq 1
$$

where $G_{I C}, G_{\text {IIC }}$ are the critical strain energy release rates for modes I and II. Whenever the disbond shape has changed, a subsequent FE analysis is performed to find the forces and displacements in the spring elements. When the disbond front is steady, that is, no more spring fails, a node at the lead crack tip is released, and by applying the MVCCT [16] for the lead crack in the substrate, the SERR $\left(G_{\mathrm{I}}\right)$ for that crack length is calculated. The $\operatorname{SIF}\left(K_{\mathrm{I}}\right)$ can be obtained from $G_{\mathrm{I}}$ by [19]

$$
\begin{aligned}
K_{\mathrm{I}} & =\sqrt{G_{\mathrm{I}} E} \quad \text { (plane stress) } \\
K_{\mathrm{I}} & =\sqrt{\frac{G_{\mathrm{I}} E}{1-v^{2}}} \quad \text { (plane strain) }
\end{aligned}
$$

where $E$ is the elastic modulus and $v$ is the Poisson's ratio of the substrate material.

Normalizing the SIF obtained from Eq. (3) by the stress intensity factor of an infinitely large plate under uniform remote stress $\left(\sigma_{\infty}\right)$, the dimensionless $\operatorname{SIF}(\beta)$ is obtained

$$
\beta=\frac{K_{\mathrm{I}}}{\sigma_{\infty} \sqrt{\pi a}}
$$

where $a$ is the crack length for a single-edge notch sample or halfcrack length for center-crack geometry [19]. When the lead crack is increased by $\Delta a$ and the new disbond front is computed, a new $K_{\mathrm{I}}$ for

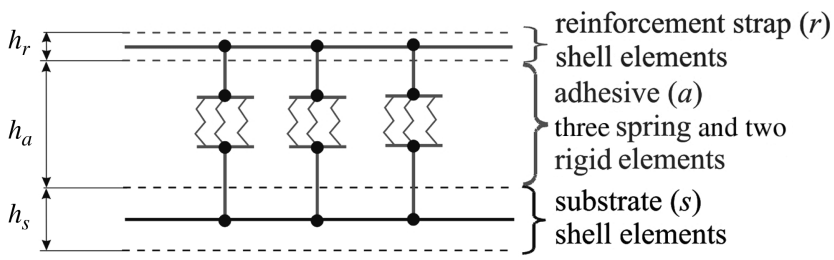

Fig. 2 Diagram of the employed finite elements for modeling the substrate plate, strap, and adhesive in the FE models. Spring nodes are coincident in the model but for the sake of clarity are presented as separated. 
the new crack length is obtained. Eventually, a SIF solution as a function of crack length is obtained. Integrating the SIF solution using either the Paris equation [20] [Eq. (5)] or the NASA developed crack growth calculation routine called the NASGRO equation [17], the FCG life is obtained:

$$
\frac{\mathrm{d} a}{\mathrm{~d} N}=C(\Delta K)^{n}
$$

where $N$ is the number of load cycles, $\Delta K$ is the SIF range under the cyclic load, and $C$ and $n$ are material constants. (Even though the NASGRO equation is more accurate than the Paris law, data for every material are not available in the AFGROW database [17].) For new materials, the Paris equation is often used with available $\frac{\mathrm{d} a}{\mathrm{~d} N}$ data. A flowchart of the computation program is illustrated in Fig. 3 .

To separate the two effects of strap stiffness (due to the material selection and strap dimension) and thermal residual stresses (induced by an elevated cure temperature), the test and modeling work reported in this paper are all based on the room temperature cure cases, that is, the thermal residual stress effect is not included. When curing samples at an elevated temperature, the residual stresses arising from the mismatch of the thermal expansion coefficients of the substrate and strap materials will affect the stress intensity factor values and hence the crack growth rates. This part of the work is ongoing, and part of the results are reported in [21].

\section{B. Considerations of Disbond Growth Under Fatigue Load}

An original feature of the aforementioned mentioned model is that the adhesive disbond growth is interactively simulated. Most of the literature on patch repairs is based on prescribing a disbond size and shape as a function of the substrate crack length by observing the test results $[\underline{8}, \underline{12}, \underline{13}]$.

Delamination growth under fatigue loads in the literature may be computed by Paris-type laws [22-24]:

$$
\frac{\mathrm{d} l}{\mathrm{~d} N}=f(\Delta G)
$$

where $\mathrm{d} l$ is the incremental length of disbond and $\Delta G$ the SERR range under fatigue load. These methods calculate $\Delta G$ and then integrate the chosen law of Eq. (6) to predict the fatigue delamination growth life [25]. A major limitation of these laws is that, unlike the crack growth equations for metallic structures, the database of material constants of different substrate/strap bonds with a specific adhesive has not yet been developed, hence the use of this equation is very limited.

Cohesive elements have also been used in the literature to model disbond in composite materials [26]. These cohesive elements have also been employed to study the effect of the adhesive properties and its interaction with the plasticity of the substrate for a steel plate reinforced by a carbon-epoxy plate by Bocciarelli et al. [27]. Another way of modeling delamination has been developed by Xie and Biggers [28,29]. A new finite element composed of two 8-node plate elements and three spring elements has been implemented in the ABAQUS code. This element calculates the SERR through the MVCCT inside the specially developed element itself, and the springs within this element will be deleted when broken using a mixed failure criterion. In this way, a moving delamination front with an arbitrary shape can be analyzed using a stationary mesh.

In the modeling technique presented in this paper, the disbond analysis is based on the same idea of Xie and Biggers [28,29]. Through the MVCCT, the SERR is computed on the crack front keeping memory of the disbond direction. Using a mixed mode failure criterion [Eq. (2)], the adhesive elements that failed are known and will be deleted to simulate adhesive disbond. This could be called an "almost-static" delamination growth, because it does not entirely take into account the disbond growth due to the fatigue load. However, it must be said that the disbond growth in patch repair and crack retarder problems is mostly due to the high stress arising from the stress "singularity" in the cracked substrate rather than from the fatigue load history.

It should be noted that, due to the disbond, the $\beta$ solution, which is just a function of the geometry in the classical linear elastic fracture mechanics (LEFM) framework, will be an indirect function of the applied load. In fact, the disbond shape, which depends on the applied load, affects the geometry of the bonded plate and this will change the $\beta$ solution. However, it is still convenient to use $\beta$ as a nondimensional SIF to describe the crack growth driving force, which is expressed as independent of the applied load. In our future work, we intend to derive a group of $\beta$ vs $a$ relations corresponding to different applied stress levels so that the users can select the correct curve or interpolate for intermediate load levels. It is more convenient to use the $\beta$ vs $a$ relation (rather than the $K$ vs $a$ relation) for calculating crack growth rates under variable amplitude loads and for using computer packages such as the AFGROW [17].

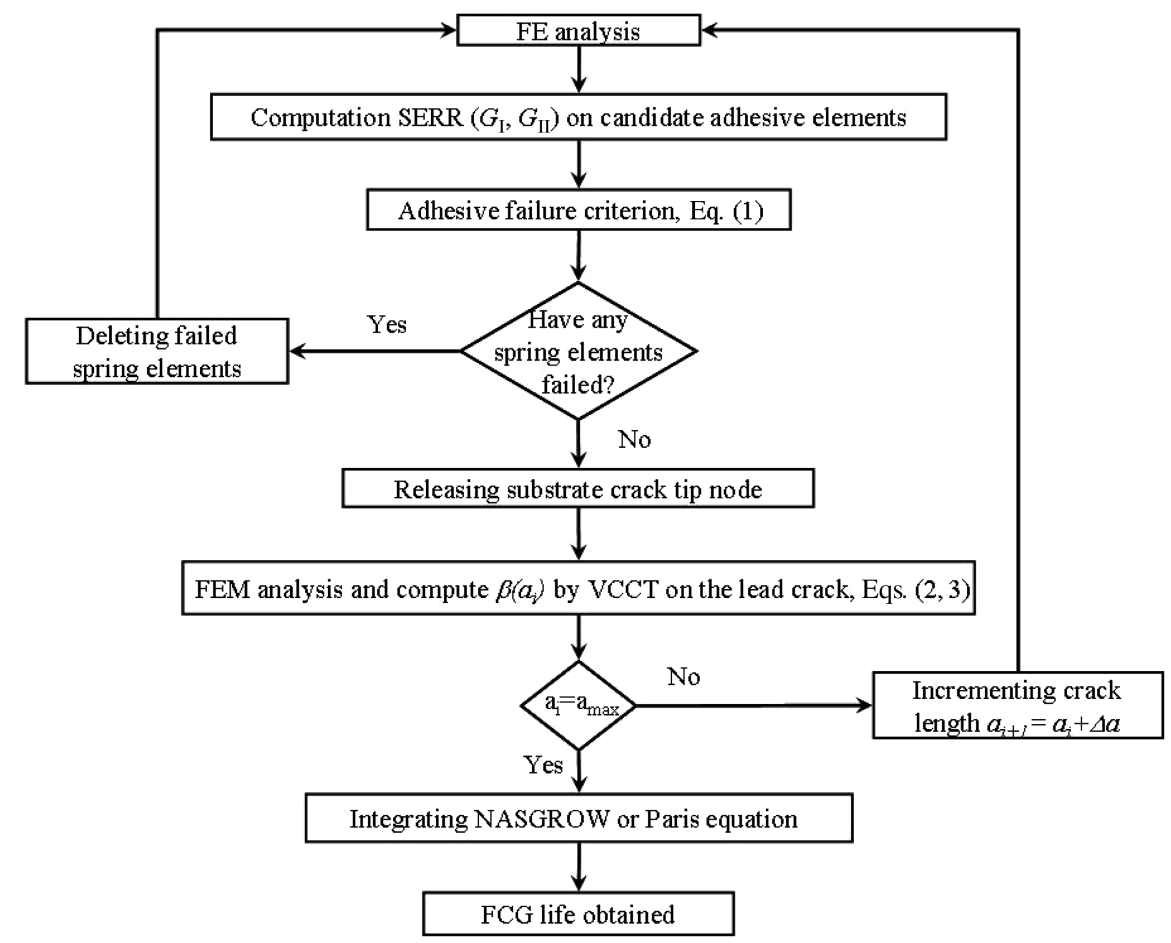

Fig. 3 Flow diagram for predicting the FCG life of a substrate with bonded crack retarders. 


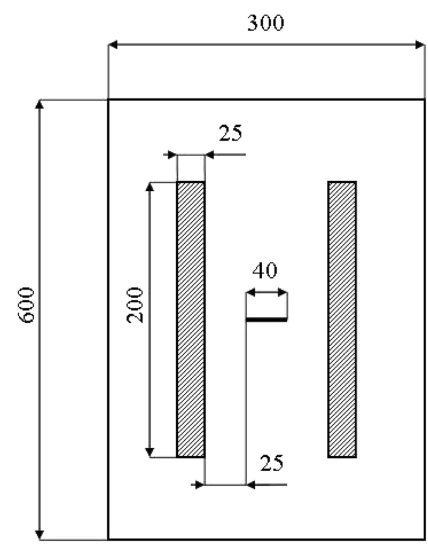

a) Middle-crack tension $M(T)$ specimen with straps. Sketch is not to scale.

Fig. 4 Geometry and dimension of two test specimens.

\section{Results and Discussions}

The test samples include a middle-crack tension, $\mathrm{M}(\mathrm{T})$, made of 2024-T351 alloy, and a single-edge notch tension, SENT, made of 7085-T765, as shown in Fig. 4. The mechanical properties and thickness of the aluminum plates can be found in Table 1 . The properties of the four strap materials and an adhesive are shown in Table 2 .

\section{A. Validation by Experimental Tests}

The M(T) plate reinforced by a pair of UD carbon-epoxy-laminate straps, Fig. 4a, was modeled, and the results were compared with the experimental ones [6,7]. The critical strain energy release rates of the adhesive are $\bar{G}_{\mathrm{IC}}^{-}=100 \mathrm{~J} / \mathrm{m}^{2}$ and $G_{\mathrm{IIC}}=350 \mathrm{~J} / \mathrm{m}^{2}$. The maximum applied load was $\sigma=75 \mathrm{MPa}$, and the stress ratio was $R=\sigma_{\min } / \sigma_{\max }=0.1$.

In Fig. 5a, the calculated $\beta$ solution is plotted and compared with an unreinforced plate and a reinforced one with ideal bond (no disbond failure). It can be seen that the effect of disbond is

Table 1 Mechanical properties and the Paris law coefficients of aluminum alloy 2024-T3 employed for the $M(T)$ and aluminum alloy 7085-T7651 for the SENT samples

\begin{tabular}{lcc}
\hline \hline Material & Aluminum 2024-T3 [] & Aluminum 7085-T7651- \\
\hline$t, \mathrm{~mm}$ & 1.6 & 10 \\
$E, \mathrm{MPa}$ & 73,000 & 71,000 \\
$v$ & 0.33 & 0.33 \\
$\rho, \mathrm{g} / \mathrm{cm}^{3}$ & 2.77 & 2.77 \\
$C$ & $1.1 \times 10^{10}$ & $6.186 \times 10^{10}$ \\
$n$ & 2.601 & 2.791 \\
\hline \hline
\end{tabular}

${ }^{a}$ Test data from the material used in the study. remarkable and cannot be neglected. The predicted and measured FCG lives are shown in Fig. 5b. The largest discrepancy between the predicted life and the test is about $10 \%$. The disbond shape measured during the test is compared with the final disbond shape computed by the model and presented in Fig. 6 . The disbond shapes are in good agreement. It can be said that the code is able to calculate the $\beta$ solution, the disbond damage between the strap and substrate, and the FCG life for a reinforced plate when the adhesive is cured at room temperature.

\section{B. Parametric Study: Strap Materials \\ 1. Analysis}

Different strap materials were studied by keeping the weight of the strap constant $(4.5 \mathrm{~g})$, that is, by changing the thickness of the strap as a function of the specific volume. The selection of strap materials was performed on the $\mathrm{M}(\mathrm{T})$ specimen made of aluminum 2024-T3 (the properties and thickness are shown in Table 1). The geometry and dimension of the plate and strap can be seen in Fig. 4a. The mechanical properties of the strap materials can be found in Table 2 . The load applied to the plate was $\sigma=75 \mathrm{MPa}$, and the stress ratio was $R=0.1$. The adhesive was cured at room temperature, and the analysis was carried out in the elastic field.

First, different laminate stacking sequences were examined for the carbon-epoxy and glass-epoxy straps, then the best carbon-epoxy and glass-epoxy straps were compared with the straps made of titanium alloy and fiber-metal laminate (GLARE).

The results for the different layups of the carbon-epoxy straps are shown in Fig. 7. Figure 7a shows that the UD straps provide the lowest crack growth driving force in terms of $\beta$, and as one can see from Fig. 7b, the longest life as well. It must be said, though, that by using the $\overline{\mathrm{UD}}$ straps, disbond failure happens earlier than with other straps and in a sudden manner, that is, the strap disbonds completely before the plate fails. (Disbond is a function of the load, and the considerations hereby made are valid for the load examined).

If we consider the complete disbond of the strap as a failure criterion, then the UD strap cannot be employed. However, if we consider that the substrate is able to carry the load after the disbond until final failure, then UD straps would be the best stacking sequence (the reasons for complete disbond will be examined later). Similar ranking of stacking sequences was obtained for the glass-epoxy straps. Examining Fig. 7, we can say that carbon-epoxy or glassepoxy angle-ply laminates are not suitable for effectively retarding the crack growth. The best material, if we consider complete disbond unacceptable, is the carbon-epoxy cross-ply (CP) laminate. However, if we consider that the strap can be subjected to complete disbond, then the carbon-epoxy unidirectional laminate is the best one.

Having studied the carbon-epoxy straps, we examined other strap materials and made comparisons among the four candidate materials. Figure 8 shows the comparisons in terms of the crack growth driving force $\beta$ and the predicted FCG lives. The best one seems to be the carbon-epoxy cross ply. In fact, the carbon-epoxy UD had already been eliminated because of the largest disbond caused by high stiffness mismatch. We can find in Fig. $\underline{8 b}$ that the other good straps

Table 2 Mechanical property of the strap materials and adhesive employed in the constant weight analysis

\begin{tabular}{|c|c|c|c|c|c|}
\hline $\begin{array}{l}\text { Material } \\
\text { Type } \\
\text { Lamination }\end{array}$ & $\begin{array}{l}\text { Adhesive } \\
\text { Redux } 810\end{array}$ & $\begin{array}{c}\text { Carbon epoxy [7] } \\
\text { M21/T800 } \\
\theta_{1} / \theta_{2} / \theta_{2} / \theta_{1}\end{array}$ & $\begin{array}{c}\text { S glass epoxy } \\
\text { Generic } \\
\theta_{1} / \theta_{2} / \theta_{1}\end{array}$ & $\begin{array}{c}\text { GLARE } \mathrm{c} \\
1 \\
2 / 1\end{array}$ & $\begin{array}{l}\text { Titanium }- \\
\text { Generic }\end{array}$ \\
\hline$t, \mathrm{~mm}$ & 0.2 & $4 \times 0.125$ & $0.125 / 0.2 / 0.125$ & 0.36 & 0.2 \\
\hline$E_{1}, \mathrm{MPa}$ & 1900 & 171,000 & 43,000 & 66,000 & 110,000 \\
\hline$E_{2}, \mathrm{MPa}$ & 1900 & 17,200 & 8900 & 54,000 & 110,000 \\
\hline$G_{12}, \mathrm{MPa}$ & 621 & 5100 & 4500 & 16,000 & 41,353 \\
\hline$v_{12}$ & 0.52 & 0.42 & 0.27 & 0.31 & 0.33 \\
\hline$\rho, \mathrm{g} / \mathrm{cm}^{3}$ & 1.1 & 1.8 & 2 & 2.52 & 4.51 \\
\hline
\end{tabular}

${ }^{a}$ Data available online at www.hexcel.com [retrieved Dec. 2006].

bata available online at http://composite.about.com/library/data/blg-sgepoxy.htm [retrieved Dec. 2006]

[32].

${ }^{\mathrm{d}} \overline{\mathrm{Gen}}$ eric properties. 


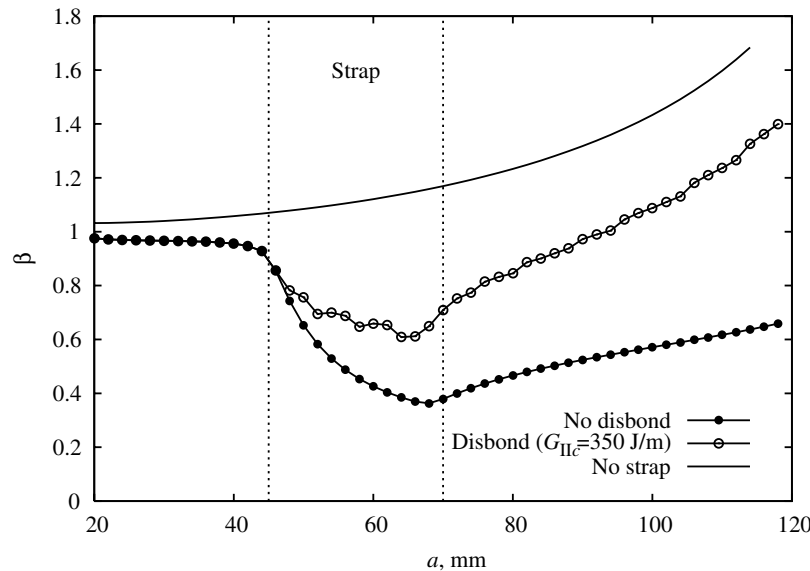

a) Calculated $\beta$ solutions

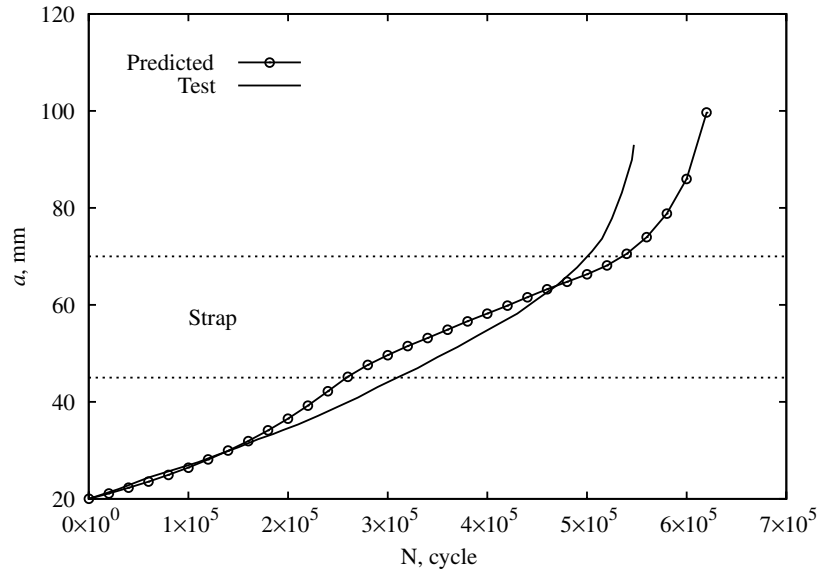

b) FCG lives of $M(T)$ sample with straps

Fig. $5 M(T)$ sample with and without straps; test [ $[\underline{6}]$ and predicted results.

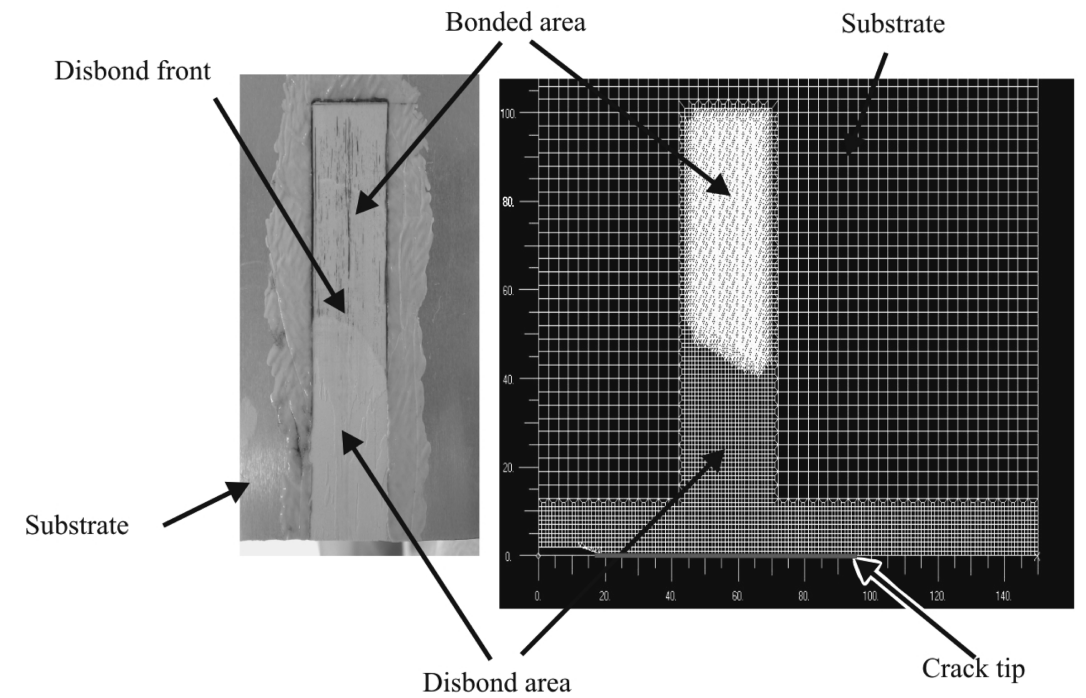

Fig. 6 Comparison of disbond front between the experimental measurement and the calculated result. M(T) sample with carbon strap. Strap position: 45-70 mm; crack tip: $a=96 \mathrm{~mm}$.

are made of GLARE and the titanium alloy. Discussions on other selection criteria for strap materials are reported in Sec. IV.B.4.

\section{Discussion}

From the preceeding results, it can be inferred that the important design parameter is the stiffness of the strap in the direction

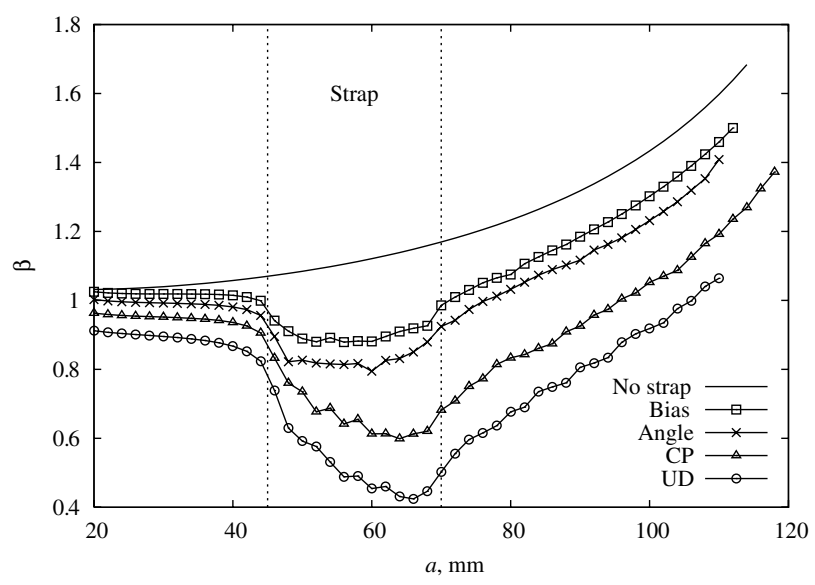

a) $\beta$ solutions perpendicular to the substrate crack propagation. The stiffness of a strap is associated with the product of the Young's modulus $(E)$ and the cross-sectional area. In fact, a stiffer strap is able to reduce the crack-tip SIF (or $\beta$ ) when the crack enters the strap region and propagates under the strap, the so-called strap stiffening effect. This phenomenon is similar to the crack growth in a skin-stringer panel, in

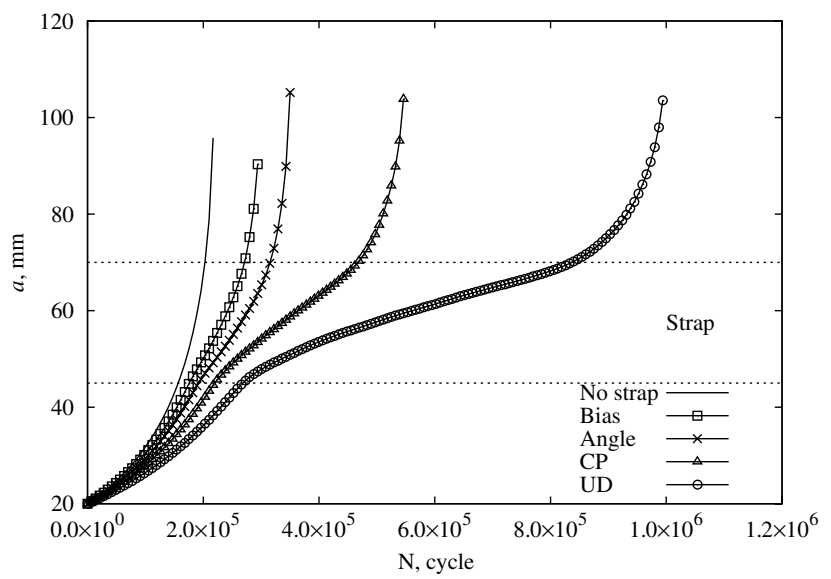

b) Predicted FCG lives

Fig. 7 Comparison of different carbon-epoxy strap layup configurations attached to the $\mathrm{M}(\mathrm{T})$ sample. Layup patterns: UD [0] ${ }_{4}$, CP $[90 / 0]_{s}$, angle $[30 / 60]_{s}$, bias $[-45 / 45]_{s}$. 


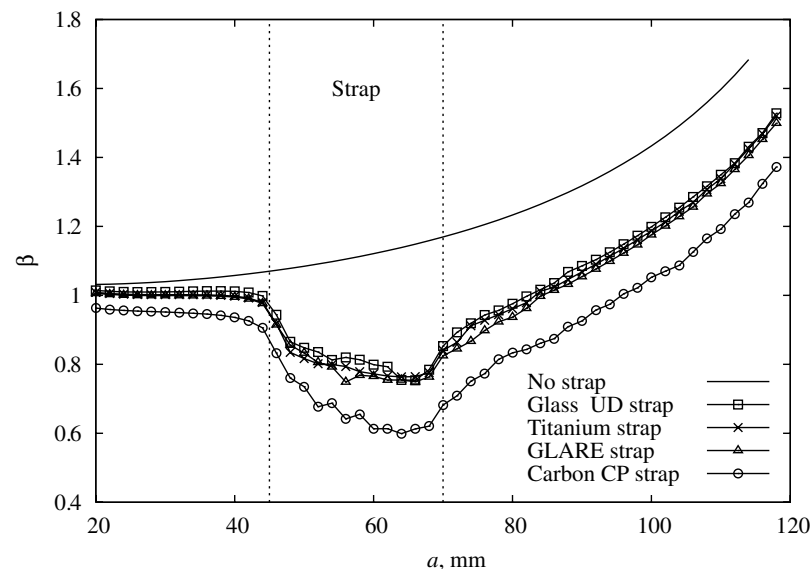

a) Calculated $\beta$ solutions

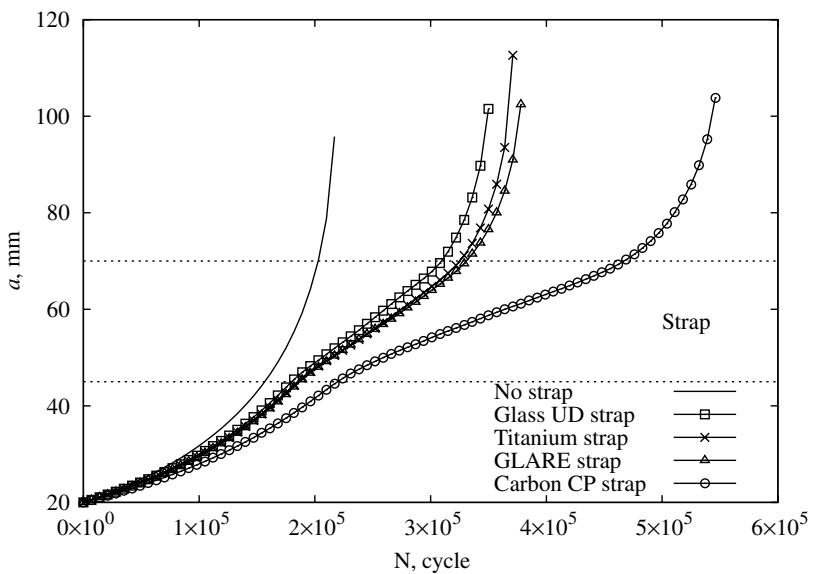

b) Predicted FCG lives

Fig. 8 Comparison of different strap materials. M(T) sample.

which case the stiffness of the stringer (riveted to the skin sheet) is important to the $\beta$ function. For example, the relative stiffness $S$ is defined as the ratio of the in-plane extensional stiffness of the stiffener and the skin sheet and is given by [30]

$$
S=A E_{2} / b t E_{1}
$$

where $A$ is the cross-sectional area of the stiffener, $t$ is the thickness of the skin sheet, $b$ is the stiffener pitch, and $E_{1}$ and $E_{2}$ are the Young's modulus of the sheet and stiffener, respectively. In a similar way, a parameter to quantify the stiffening effect of the strap was defined by Schjive [3] for bonded reinforced plates:

$$
\mu=\frac{\sum_{i=1}^{n} E_{r}^{i} A_{r}^{i}}{E_{s} A_{s}+\sum_{i=1}^{n} E_{r}^{i} A_{r}^{i}}
$$

where $E_{r}, E_{s}, A_{r}$, and $A_{s}$ correspond to the longitudinal Young's modulus and the cross-section area of the reinforcement strap and the substrate, respectively, and $n$ is the total number of straps. The stiffening effect can be seen in Figs. $7 \mathrm{a}$ and $\underline{8 \mathrm{a}}$; when the crack tip is before and under the strap, the $\bar{\beta}$ solution is lower than the unreinforced plate. Another positive effect is the so-called bridging effect. When the crack tip has passed the strap region, the strap will produce a bridging (or traction) force to reduce the crack opening displacement and thus a reduction on the $\beta$ value (refer to Figs. 7a and 8 a). This effect can also be characterized by the stiffness ratio [Eq. $\overline{(8)}$ ].

Stiffness also contributes to other mechanisms involved in bonded structures as summarized in Table $\underline{3}$, for example, disbond failure at the interface due to shear load transfer. A stiffer strap will cause a bigger stiffness mismatch with the substrate material and hence a larger disbond due to the fact that more stress will be transferred from the substrate to the strap. A tradeoff between strap stiffness and adhesive toughness is necessary during the selection of the strap materials. Other mechanisms are the secondary bending effect due to a one-sided strap and thermal residual stresses generated by the elevated temperature curing process of the adhesive, which promote crack opening and bending. The last is not considered in this paper, because the adhesive was cured at room temperature. However, it is included in the mechanisms in Table $\underline{3}$ for completeness.

\section{Critical Disbond}

The complete disbond shown by the UD carbon-epoxy materials was further studied to find reasons and causes. The same plate configuration of the previous problem was employed (see Fig. 4a). Two UD carbon-epoxy straps of different thicknesses $(t=0.25$ and $0.5 \mathrm{~mm})$ and one cross-ply carbon-epoxy strap $(t=0.5 \mathrm{~mm})$ were examined under different applied load values. The results can be seen in Fig. 9. For each given applied stress $(\sigma)$, the critical crack length $\left(a_{\text {crit }}\right)$ can be found at which the complete strap disbond failure will occur. Intuitively, the complete disbond will depend on the mismatching between the stiffness of the aluminum substrate and the strap. In fact, the stiffer the strap, the more load will be transferred from the substrate to the reinforcement through the adhesive, and the adhesive will fail earlier. This observation can be demonstrated by calculating the membrane stiffness of the laminates $\mathbf{A}$ (see Appendix). It must be noted that the stiffest material is the UD carbon

\begin{tabular}{|c|c|c|c|c|}
\hline \multirow[b]{3}{*}{ Mechanism } & Positive effect & \multicolumn{3}{|c|}{ Negative effect } \\
\hline & \multirow{2}{*}{ Stiffening and bridging } & \multirow[t]{2}{*}{ Disbond } & \multirow[t]{2}{*}{ Secondary bending } & \multirow[t]{2}{*}{ Thermal residual stresses } \\
\hline & & & & \\
\hline Description & $\begin{array}{l}\text { Reduce crack-tip stress and } \\
\text { crack opening; slow down } \\
\text { crack growth }\end{array}$ & Reduce the bridging effect & $\begin{array}{l}\text { Cause higher crack growth rate } \\
\text { and curved crack front }\end{array}$ & $\begin{array}{l}\text { Tensile stresses accelerate crack } \\
\text { growth rate }\end{array}$ \\
\hline \multirow{4}{*}{$\begin{array}{l}\text { Influential } \\
\text { parameter }\end{array}$} & \multirow{4}{*}{$\begin{array}{l}\text { 1) Strap stiffness: geometry } \\
\text { and mechanical properties }\end{array}$} & \multirow{4}{*}{$\begin{array}{l}\text { 1) Adhesive toughness and } \\
\text { mechanical properties } \\
\text { 2) Stiffness of strap and } \\
\text { substrate }\end{array}$} & 1) Plate and strap geometries & 1) Plate and strap geometry \\
\hline & & & 2) Stiffness of strap and & 2) Coefficients of thermal \\
\hline & & & substrate & $\begin{array}{l}\text { expansion } \\
\text { 3) Strap and substrate stiffness }\end{array}$ \\
\hline & & & & 4) Curing temperature \\
\hline
\end{tabular}

Table 3 Summary of mechanisms involved in bonded reinforced structures 
epoxy $(t=0.5 \mathrm{~mm})$, but even though a thicker cross-ply carbon epoxy $(t=0.5 \mathrm{~mm})$ is slightly stiffer than a thinner UD $(t=0.25 \mathrm{~mm})$, critical disbond happens later for the former than for the latter under the same load (see equations in the Appendix and Fig. 9). It can be said that critical disbond does not only depend on the mismatching between the stiffness of the substrate and the strap, but also on the difference between the values $A_{11}$ and $A_{22}$ of the membrane stiffness of the laminate. This means that in terms of complete disbond, cross-ply or fabric laminates should behave better than the unidirectional ones, but more plies are necessary to obtain a material that is as stiff as the UD laminate. To summarize, the UD composites should be employed to obtain a life target, but if they suffer from complete disbond under a given load and geometry, then cross-ply or fabric laminates could be employed to achieve that life target without critical disbond failure.

\section{Other Selection Criteria for Strap Materials}

The ranking of the strap materials has been based on the crack growth life, which is mainly influenced by the stiffness ratio of the strap over the substrate [Eq. (8)]. It should be acknowledged that fatigue crack growth life is not the only sizing criterion for aircraft structures, and, as a result, some of the best solutions for improved crack growth may not be feasible for real design applications. For example, galvanic corrosion is a concern for long-term durability when bonding carbon-epoxy composites to aluminum structures. Another important design criterion is the notch strain to failure limit. Because there are holes in the aluminum structure as well as in the reinforcement straps, the realistic maximum strain of a metallic wing box at ultimate load is about $2-2.5 \%$. The maximum notch strain to failure of carbon-fiber composites is around $0.8-1.0 \%$. Hence, if we use a strap that has a blunt notch strain to failure much below that of the metallic structure, we could either risk the failing of the strap before reaching the structure ultimate load or have to limit the maximum design strain (and, therefore, maximum stress) allowable for the metallic structure, resulting in very conservative design. When taking into account the thermal residual stress effect arising from an elevated cure temperature, the material ranking could also change [21]. Nevertheless, this paper has presented a worthwhile research that has established the modeling approach for bonded structures and has explored the effect of strap stiffness for a wide range of materials, from an isotropic ductile alloy to three composite laminates, including a range of stacking sequences.

\section{Parametric Study: Strap Dimensions and Positions}

Different strap dimensions and positions were studied for a crossply carbon-epoxy strap on the SENT specimen (Fig. 4b) made of aluminum alloy 7085-T7651 (Table 1) with a thickness of $10 \mathrm{~mm}$. The load applied to the plate was $\sigma=53.57 \mathrm{MPa}$ and the stress ratio was $R=0.1$. To classify the different strap configurations, notations are defined as $w X X d Y Y t Z Z$, where $w$ is the width of the strap, $d$ is

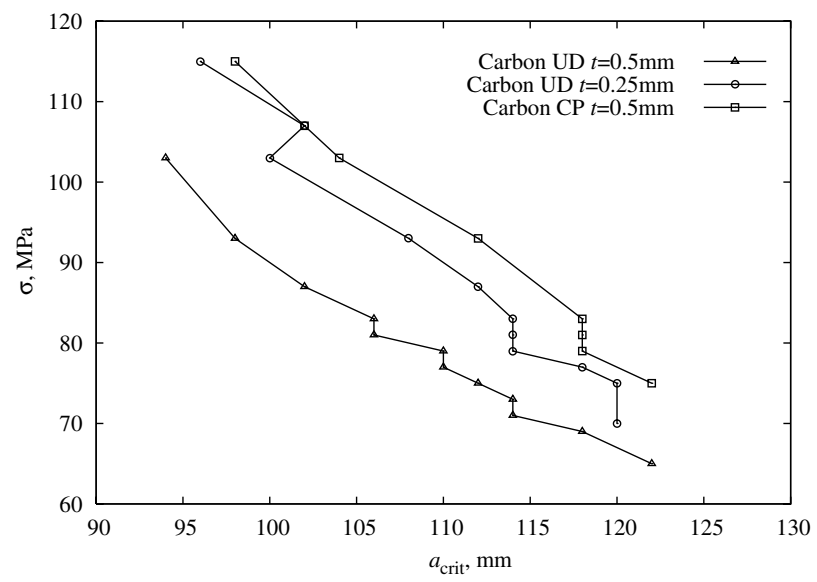

Fig. 9 Crack length of complete disbond for three different strap configurations under different load values. the distance between the strap edge and initial crack tip, and $t$ is the thickness of the strap. For example, $w 25 d 50 t 0.5$ defines a strap that is $25 \mathrm{~mm}$ wide, $50 \mathrm{~mm}$ from the initial crack tip, and $0.5 \mathrm{~mm}$ thick.

The goal is to maximize the number of cycles to failure $\left(N_{c}\right)$ compared with that of the unreinforced plate $\left(N_{\mathrm{Al}}\right)$ and minimize the strap weight $(m)$ by working on the strap width $(w)$, distance $(d)$, and thickness $(t)$. A parameter $(e)$ was proposed. It indicates the percentage of life improvement with respect to the plain panel per gram weight of strap:

$$
e=\frac{\frac{N_{c}-N_{\mathrm{Al}}}{N_{\mathrm{Al}}} 100}{m}
$$

To limit the interactions between the different parameters and truly understand their effect on the FCG life, each design variable has been studied by keeping the other constant. The distance $d$ is the simplest and clearest parameter. The results are shown in Fig. 10. Examining Figs. $10 \mathrm{a}$ and $10 \mathrm{~b}$, we can say that the closer the strap is to the crack tip, the better it behaves in terms of both $e$ and $N_{c}$. Obviously, having a strap very close to the crack tip would require a short gap between one strap and the others, that is, a small strap pitch in the wing box. We decided to keep the strap distance at $25 \mathrm{~mm}$ from the crack tip and study the other two parameters.

The effects of thickness $t$ and width $w$ are more complicated. In Figs. $10 \mathrm{c}$ and $10 \mathrm{~d}$, one can see that $e$ and $N_{c}$ are in an opposite trend. When $N_{c}$ increases, $e$ decreases; an absolute maximum cannot be found. However, a useful tool has been developed to lead designers to the best possible strap choice once the life target and weight limit have been decided. The interaction between the different design variables ( $w$ and $t$ ) are included in this graph because the life is plotted for different strap widths and thicknesses. The so-called project graph is presented in the next section.

\section{Project Graph}

The project graph is a diagram showing the relation between strap variables and fatigue life, which can lead the designers to the best strap choice for a given life target (see Fig. 11). It has two $y$ axes. The left one is the percentage of life increment $\Delta N$ [Eq. (10)], and the right $y$ axis shows the percentage of the mass increment $\Delta m$ [(Eq. (11)]:

$$
\Delta N=\frac{N_{c}-N_{\mathrm{Al}}}{N_{\mathrm{Al}}} \times 100
$$

$$
\Delta m=\frac{\left(m_{s}+m_{\mathrm{Al}}\right)-m_{\mathrm{Al}}}{m_{\mathrm{Al}}} \times 100=\frac{m_{s}}{m_{\mathrm{Al}}} \times 100
$$

where $N_{c}$ is the FCG life of the plate with the strap, $N_{\mathrm{Al}}$ is the FCG life of the substrate without the strap, $m_{s}$ is the weight of the strap, and $m_{\mathrm{Al}}$ is the weight of the substrate.

The $x$ axis shows the width ratio $\left(w_{s} / w_{\mathrm{Al}}=\right.$ strap width/substrate width). In the graph there are three pairs of curves. Each pair refers to a specific thickness ratio $\left(t_{s} / t_{\mathrm{Al}}=\right.$ strap thickness/substrate thickness) and is indicated by a different symbol (triangles, squares, circles). Each pair has two curves; the solid line refers to the life increment and is read on the left axis, and the dashed line refers to the mass increment and is read on the right axis. An example project graph for the cross-ply carbon epoxy is shown in Fig. 11. Dimensions, geometries, and load conditions are given in Sec. IV.C. The example shown in Fig. 11 is explained as follows. First, a mass limit should be decided; in this case, a weight increment of $6 \%$ is fixed. Consequently, the upper right part of the graph in the gray box of Fig. 11 cannot be accepted due to too much weight gain. If we want to achieve a life improvement of $250 \%$, we will go into the gray part, and this means that that level of life improvement cannot be reached with the weight limit. If we want to achieve a life increment of $100 \%$, we will find two solutions, that is, $w 20 d 25 t 6$ and $w 48 d 25 t 3$ (see arrows in Fig. 11). Between these two solutions, we can find the lighter one, that is, $w 20 d 25 t 6$ with a weight gain of $20 \mathrm{~g}$, or nearly a $3 \%$ weight increment. 


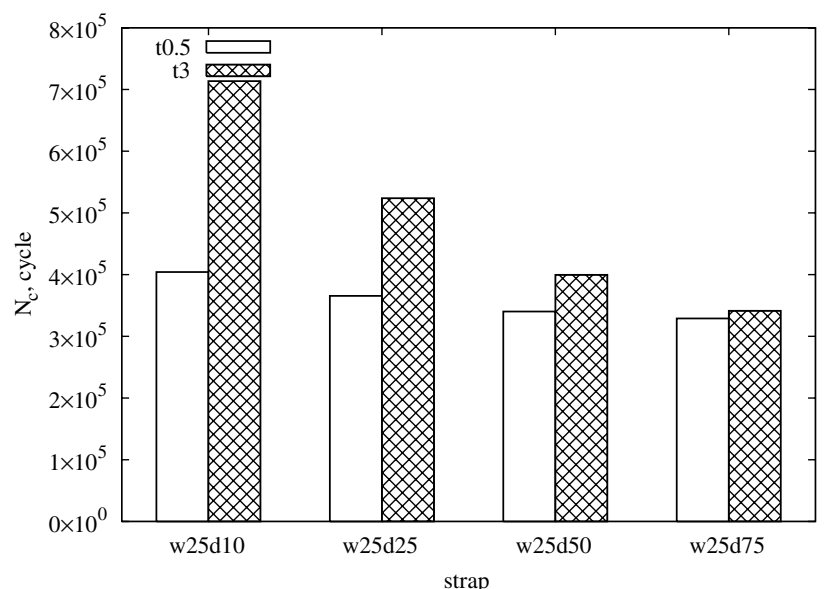

a) FCG life for different strap distances $(d)$

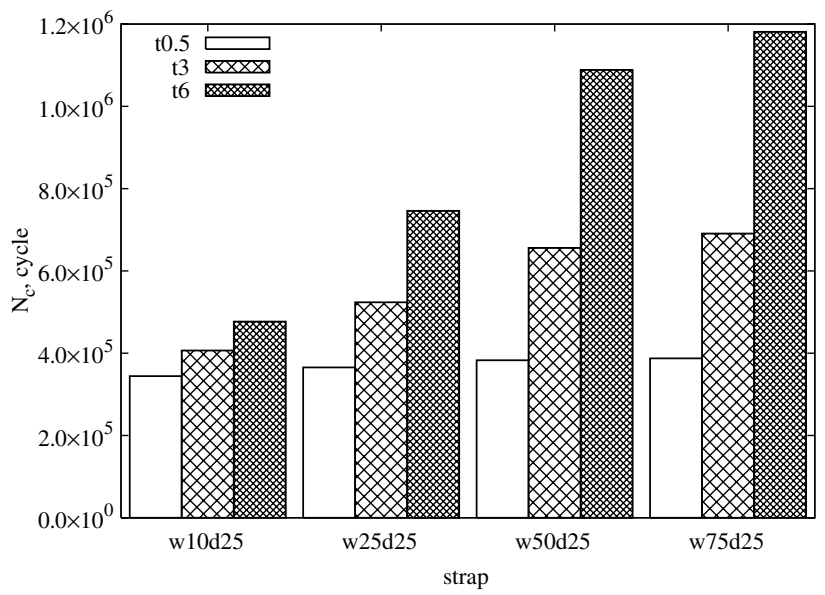

c) FCG life for different strap widths ( $w$ ) and thicknesses $(t)$

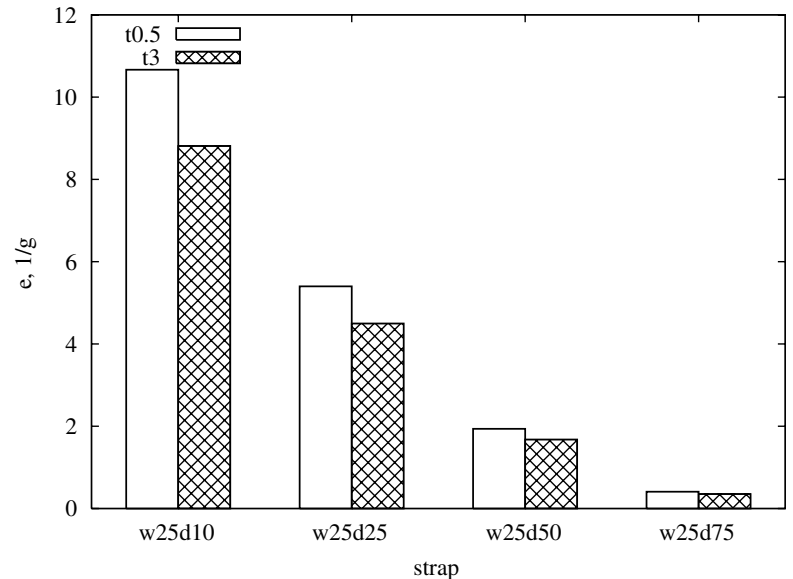

b) $\boldsymbol{E}$ for different strap distances $(d)$

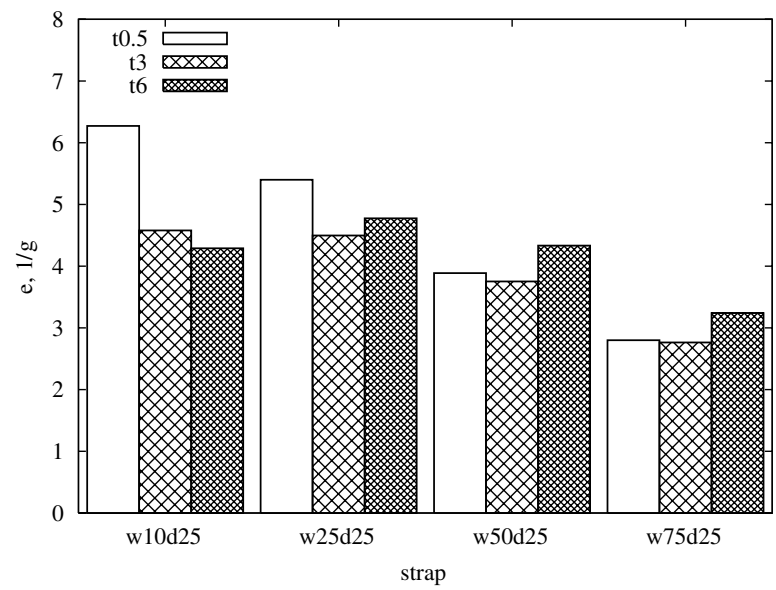

d) $E$ for different strap widths ( $w$ ) and thicknesses $(t)$

Fig. 10 Results for different strap positions, widths, and thicknesses. SENT sample.

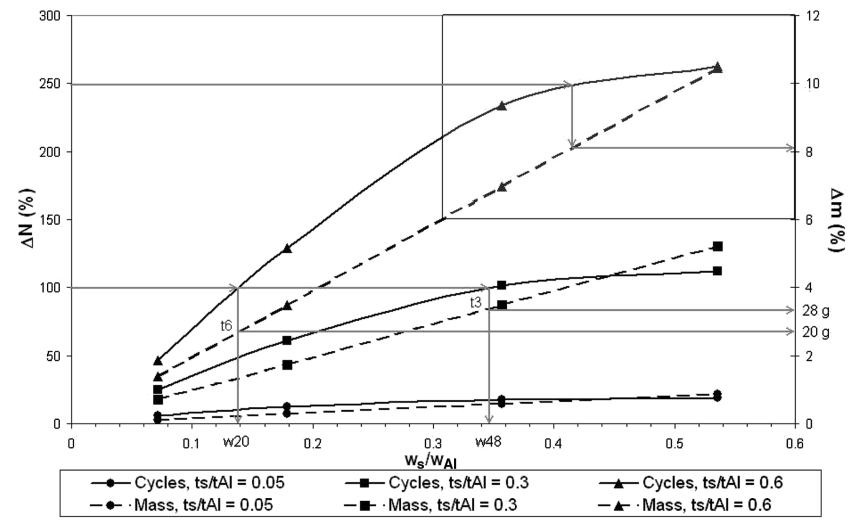

Fig. 11 Example of use of the project graph for the choice of the strap geometry (carbon cross ply).

To summarize, using the project graph, one can find the strap geometries with respect to the mass limit and life target and, moreover, the lightest strap for the defined conditions.

\section{Conclusions}

A modeling approach has been developed for predicting adhesive disbond failure and fatigue crack growth life in substrates made of aerospace aluminum alloys and bonded with crack retarder straps. A novel feature is that the adhesive disbond growth is interactively calculated rather than prescribed as a function of the of the substrate crack length obtained from experimental data.
The effect of various strap configurations on the crack growth lives of the SENT specimen has been modeled to cover different strap materials, strap dimensions, and strap locations. In the cases of room temperature cure, that is, in the absence of thermal residual stresses, the important design parameters are identified as the elastic modulus of the strap material, strap cross-sectional area, and strap location.

The adhesive toughness is another influential parameter. Because high strap stiffness promotes early disbond due to high load transfer from the substrate to the strap, a tradeoff between the adhesive toughness and the strap stiffness should be sought. When using laminated composite straps, cross-ply laminates are advisable for weaker adhesives, because a complete disbond can be retarded. On the other hand, for tougher adhesives, the best stacking sequence is the unidirectional layup provided that under the load spectrum the strap does not disbond completely. In terms of the strap position, the closer the strap is to the crack tip, the better the life improvement will be.

Finally, when the aforementioned mentioned parameters are defined, the best strap dimensions in terms of width and thickness can be found by using the project graph developed in this study.

\section{Appendix}

The membrane stiffness of a laminate $\mathbf{A}$ can be calculated as follows [31]:

$$
\mathbf{A}=\sum_{k=1}^{k=N_{l}} \int_{h_{k-1}}^{h_{k}} \mathbf{C}^{k} \mathrm{~d} z=\sum_{k=1}^{k=N_{l}} \mathbf{C}^{k}\left(h_{k}-h_{k-1}\right) \mathrm{d} z
$$

where $N_{l}$ is the number of layers, $\mathbf{C}^{k}$ the material matrix for the $k$ th layer, and $h_{k}$ the height of the $k$ th layer. The value of this matrix 
for the three strap thicknesses and layups yield

$$
\begin{aligned}
\mathbf{A}_{U D 0.5}= & {\left[\begin{array}{ccc}
87044 & 3677 & 0 \\
3677 & 8755 & 0 \\
0 & 0 & 25590
\end{array}\right](\mathrm{kN} / \mathrm{mm}), } \\
\mathbf{A}_{U D 0.25}= & {\left[\begin{array}{ccc}
43522 & 1838 & 0 \\
1838 & 4377 & 0 \\
0 & 0 & 1275
\end{array}\right](\mathrm{kN} / \mathrm{mm}) } \\
\mathbf{A}_{C P 0.5}= & {\left[\begin{array}{ccc}
47900 & 3677 & 0 \\
3677 & 47900 & 0 \\
0 & 0 & 2550
\end{array}\right](\mathrm{kN} / \mathrm{mm}) }
\end{aligned}
$$

where $\mathbf{A}_{U D 0.5}, \mathbf{A}_{U D 0.25}$, and $\mathbf{A}_{C P 0.5}$ are, respectively, the membrane stiffness for the unidirectional $0.5 \mathrm{~mm}$ thick, unidirectional $0.25 \mathrm{~mm}$, and cross-ply $0.5 \mathrm{~mm}$ laminates.

\section{Acknowledgments}

The authors are grateful to Airbus UK and Alcoa, Inc., for providing financial support.

\section{References}

[1] Schmidt, H. J., and Schmidt-Brandecker, B., "Damage Tolerance Design and Analysis of Current and Future Aircraft Structure," AIAA Paper 2003-2784, July 2003.

[2] Pacchione, M., and Telgkamp, J., "Challenges of the Metallic Fuselage," 25th International Congress of Aeronautical Science, International Council of the Aeronautical Sciences [CD-ROM], http:// www.icas2006.org/index2.php, 2006.

[3] Schijve, J., "Crack Stoppers and ARALL Laminates," Engineering Fracture Mechanics, Vol. 37, No. 2, 1990, pp. 405-421. doi:10.1016/0013-7944(90)90050-Q

[4] Heinimann, M. B., Bucci, R. J., Kulak, M., and Garratt, M., "Improving Damage Tolerance of Aircraft Structures Through the Use of Selective Reinforcement," Proceedings of the 23rd Symposium of the International Committee on Aeronautical Fatigue, DGLR, Munich, Germany, June 2005, pp. 197-208.

[5] Zhang, X., and Li, Y., "Damage Tolerance and Fail Safety of Welded Aircraft Wing Panels," AIAA Journal, Vol. 43, No. 7, 2005, pp. 16131623.

doi: $10.2514 / 1.10275$

[6] Colavita, M., Bowler, A., Zhang, X., and Irving, P. E., "Adhesively Bonded CFRP Straps as Fatigue Crack Growth Retarders on AA2024T3," Proceedings of SAMPE Conference 2006, ASM, Vol. 13C, Corrosion: Environments and Industries, http://www.sampe.org/store/ paper.aspx?pid=3542, April 2006.

[7] Bowler, A., "Crack Stoppers and Fail Safety in Integral Metal Aircraft Structure,"Master's Thesis, Cranfield University, England, U.K., 2005.

[8] Colombi, P., Bassetti, A., and Nussbaumer, A., "Delamination Effects on Cracked Steel Members Reinforced by Prestressed Composite Patch," Theoretical and Applied Fracture Mechanics, Vol. 39, No. 1, 2003, pp. 61-71. doi:10.1016/S0167-8442(02)00138-6

[9] Baker, A., "Crack Patching: Experimental Studies, Practical Applications," Bonded Repair of Aircraft Structures, edited by A. Baker and R. Jones, Martinus-Nijhoff, Dordrecht, The Netherlands/ Boston, 1988, pp. 107-173.

[10] Baker, A., "Fibre Composite Repair of Cracked Metallic Aircraft Components-Practical and Basic Aspects," Composites, Vol. 18, No. 4, 1987, pp. 293-308. doi:10.1016/0010-4361(87)90293-X

[11] Jones, R., and Callinan, R. J., "Finite Element Analysis of Patched Cracks," Journal of Structural Mechanics, Vol. 7, No. 2, 1979, pp. $107-$ 130.

[12] Naboulsi, S., and Mall, S., "Modelling of a Cracked Metallic Structure with Bonded Composite Patch Using the Three Layer Technique," Composite Structures, Vol. 35, No. 3, 1996, pp. 295-308. doi:10.1016/0263-8223(96)00043-8

[13] Sun, C. T., Klung, J., and Arendt, C., "Analysis of Cracked Aluminum Plates Repaired with Bonded Composite Patches," AIAA Journal, Vol. 34, No. 2, 1996, pp. 369-374.

[14] Rose, L., "A Cracked Plate Repaired by Bonded Reinforcements,"
International Journal of Fracture, Vol. 18, No. 2, 1982, pp. 135-144. doi:10.1007/BF00019638

[15] Sabelkin, V., Mall, S., Avram, J. B., "Fatigue Crack Growth Analysis of Stiffened Cracked Panel Repaired with Bonded Composite Patch," Engineering Fracture Mechanics, Vol. 73, No. 11, 2006, pp. 1553 1567. doi:10.1016/j.engfracmech.2006.01.029

[16] Krueger, R., "The Virtual Crack Closure Technique: History, Approach and Applications," NASA Langley Research Center CR-2002-211628, Hampton, VA, 2002; also International Council of the Aeronautical Sciences Rept. 2002-10, 2002.

[17] Harter, J., "AFGROW Users Guide and Technical Manual," Air Vehicles Directorate, http://www.siresearch.info/projects/afgrow/ downloads/afgrow/ddownload.php, June 2006.

[18] Tahmasebi, F., "Software Tools for Analysis of Bonded Joints," NASA/Goddard Space Flight Center TR-542, 2001.

[19] Broek, D., Elementary Engineering Fracture Mechanics, 4th ed., Martinus-Nijhoff, Dordrecht, The Netherlands/Boston1986.

[20] Paris, P., and Erdogan, F., "A Critical Analysis of Crack Propagation Laws," Journal of Basic Engineering, Transactions of the American Society of Mechanical Engineers, Series D, Vol. 85, No. 4, 1963, pp. 528-534.

[21] Zhang, X., Boscolo, M., Figueroa-Gordon, D., Allegri, G., and Irving, P. E., "Fail-Safe Design of Integral Metallic Aircraft Structures Reinforced by Bonded Crack Retarders," Engineering Fracture Mechanics (to be published).

[22] Wilkins, D. J., Eisenmann, J., Camin, R., Margolis, W., and Benson, R., "Characterising Growth in Graphite-Epoxy," Damage in Composite Materials, American Society for Testing and Materials STP 775, 1982, pp. $168-183$.

[23] Wang, A., Slomiana, M., and Buncinel, R., "Delamination Crack Growth in Composite Laminates," Delamination and Debonding of Materials, American Society for Testing and Materials STP 876, 1985, pp. $135-167$.

[24] Alderliesten, R., Schijve, J., and van der Zwaag, S., "Application of the Energy Release Rate Approach for Delamination Growth in Glare," Engineering Fracture Mechanics, Vol. 73, No. 6, 2006, pp. 697-709. doi:10.1016/j.engfracmech.2005.10.006

[25] Kardomateas, G., Pelegri, A., and Malik, B., "Growth of Internal Delamination Under Cyclic Compression in Composite Plates," Journal of the Mechanics and Physics of Solids, Vol. 43, No. 6, 1995, pp. 847-868. doi:10.1016/0022-5096(95)00012-8

[26] Camanho, P. P., Dàvila, C., and Ambur, D., "Numerical Simulation of Delamination Growth in Composite Materials," NASA TP-2001211041, Aug. 2001.

[27] Bocciarelli, M., Colombi, P., Fava, G., and Poggi, C., "Interaction of Interface Delamination and Plasticity in Tensile Steel Members Reinforced by CFRP Plates," International Journal of Fracture, Vol. 146, Nos. 1-2, 2007, pp. 79-92. doi: $10.1007 / \mathrm{s} 10704-007-9144-8$

[28] Xie, D., and, Biggers, S., Jr., "Strain Energy Release Rate Calculation for Moving Delamination Front of Arbitrary Shape Based on the Virtual Crack Closure Technique. Part 1: Formulation and Validation," Engineering Fracture Mechanics, Vol. 73, No. 6, 2006, pp. 771-785. doi:10.1016/j.engfracmech.2005.07.013

[29] Xie, D., and Biggers, S., Jr., "Strain Energy Release Rate Calculation for Moving Delamination Front of Arbitrary Shape Based on the Virtual Crack Closure Technique. Part 2: Sensitivity Study on Modeling Details," Engineering Fracture Mechanics, Vol. 73, No. 6, 2006, pp. $786-801$. doi:10.1016/j.engfracmech.2005.07.014

[30] Rooke, D. P., and Cartwright, D. J., Compendium of Stress Intensity Factors, Her Majesty's Stationery Office, London, 1976.

[31] Reddy, J., Mechanics of Laminated Composite Plates and Shells: Theory and Analysis, Classical and First-Order Theories of Laminated Composite Plates, CRC Press, Boca Raton, FL, 1997, Chap. 3, pp. 109164.

[32] Wu, G., and Yang, J. M., "The Mechanical Behavior of GLARE Laminates for Aircraft Structures," JOM, Vol. 57, No. 1, 2005, pp. 72-79. doi:10.1007/s11837-005-0067-4 